\title{
PHENOLIC COMPOSITION AND BIOLOGICAL (ANTI DIABETIC AND ANTIOXIDANT) ACTIVITIES OF DIFFERENT SOLVENT EXTRACTS OF AN ENDEMIC PLANT (HELIOTROPIUM STRIGOSUM)
}

\author{
ABDUL QAYYUM ${ }^{1}$, RAJA ADIL SARFRAZ ${ }^{1,2}$, AISHA ASHRAF,${ }^{3 *} \&$ SHAZIA ADIL ${ }^{1}$ \\ ${ }^{1}$ Department of Chemistry University of Agriculture, Faisalabad, (38040), Pakistan \\ ${ }^{2}$ Central Hi-Tech Laboratory, University of Agriculture, Faisalabad, (38040), Pakistan \\ ${ }^{3}$ Department of Chemistry, Gout. College Women University, Faisalabad, (38040), Pakistan
}

\begin{abstract}
Heliotropium strigosum plant is widely used in traditional medicines for treatment of various ailments. In current study, an effort was made to evaluate phenolic profile as well as antidiabetic and antioxidant activities of crude methanol extract and different solvent (n-hexane, ethyl acetate, chloroform and aqueous) fractions of H. strigosum. Total phenolic contents were determined by spectrophotometric assay. Polyphenolic compounds in crude methanol extract and each solvent fraction were identified by reverse phase high performance liquid chromatography (RP-HPLC). Antioxidant and antidiabetic activities were determined using DPPH and $\alpha$-amylase inhibition assays, respectively. The outcome of spectrophotometric assay showed that methanol extract had higher amount of total phenolic $(84.50 \pm 0.06 \mu \mathrm{g} \mathrm{GAE} / \mathrm{mg}$ of plant extract) contents than aqueous, ethyl acetate, chloroform and n-hexane fractions, respectively. The RP-HPLC analysis revealed the maximum number of phenolic (chromotropic acid, quercetin, trans-4-hydroxy-3-methoxy cinnamic acid, vanillic acid, gallic acid, caffeic acid, $\mathrm{m}$-coumaric acid, p-coumaric acid, syringic acid, sinapic acid and ferulic acid) compounds in methanol extract. Methanol extract $\left(\mathrm{IC}_{50}=8.97 \mu \mathrm{g} / \mathrm{mL}\right)$ exhibited the maximum antidiabetic activity followed by aqueous $\left(\mathrm{IC}_{50}=20.04 \mu \mathrm{g} / \mathrm{mL}\right)$, ethyl acetate $\left(\mathrm{IC}_{50}=27.79 \mu \mathrm{g} / \mathrm{mL}\right)$, chloroform $\left(\mathrm{IC}_{50}=56.87 \mu \mathrm{g} / \mathrm{mL}\right)$ and hexane $\left(\mathrm{IC}_{50}\right.$ $=32.16 \mu \mathrm{g} / \mathrm{mL}$ ) fractions, respectively. The outcome of antioxidant assay revealed that methanol extract was the leading one with regard to antioxidant activity at different doses (10 to $250 \mu \mathrm{g} / \mathrm{mL}$ ). The current study concludes that $H$. strigosum solvents extracts with significant phenolic profile and potent biological activities could be explored for potential uses in neutraceutical and pharmaceutical industries.
\end{abstract}

Key words: Antidiabetic; DPPH; Heliotropium Strigosum; Solvent fractions

\section{INTRODUCTION}

Heliotropium strigosum of vernacular name "Gorakhpamo" is a herb which may reach the height of $28 \mathrm{~cm}$. It is wildly distributed in hot arid regions of world including Pakistan ${ }^{1,2}$. It is traditionally used for treatment of different ailments such as constipation, muscle pains, boils and sore eyes ${ }^{3}$. It is an effective remedy for cure of snake bites. H. strigosum belongs to family Boraginaceae. Boraginaceae is scientifically known for its anti-inflammatory, antimicrobial, antineoplastic, antinociceptive, antiplasmodial, antioxidant, antitrypanosomal, nephroprotective and wound healing activities $4,5,6,7,8,9$.

Although some studies on the use of $\mathrm{H}$. strigosum as natural cytotoxic, phytotoxic, anti-inflammatory, antimicrobial and antioxidant agent are available in literature ${ }^{10,11}$, but there was complete gap of knowledge about detailed phenolic profile and antidiabetic attributes of different solvent extracts obtained from whole plant of $H$. strigosum. Therefore, in current study an effort was made to investigate the phenolic components, antidiabetic and antioxidant activities of different solvent (methanol, n-hexane, ethyl acetate, chloroform and aqueous) extracts of $H$. strigosum so as to explore their potential uses as natural antidiabetic and antioxidative agents for food and pharmaceutical industries.

\section{MATERIALS AND METHODS}

\section{Chemicals and reagents}

Phosphate buffer ( $\mathrm{pH}$ 6.9), DNSA (3,5-Dinitrosalicylic acid), starch solution, alpha amylase, DPPH, methanol, n-hexane, chloroform, ethyl acetate, hydrochloric acid and Folin-Ciocalteu reagent were obtained from Merck (Darmstadt, Germany). All other chemicals were of analytical grade and purchasedfrom Sigma Chemical Co. (St. Louis, MO, USA), unless stated otherwise.

\section{Collection of plant materials}

The dried sample of Heliotropium strigosum was collected from Chitral, Province Khyber Pakhtunkhuwa, Pakistan. The whole plant material was extensively washed with distilled water to remove dust or any other particulate matter. The shade dried whole plant material of $H$. strigosum was ground into fine powder with the help of coffee grinder (Westpoint coffee grinder, WF 9222). The powdered material was passed through seiver $(0.25 \mathrm{~mm})$. Sieved fine powdered plant material was stored in opaque screw-capped containers at room temperature.

\section{Preparation of plant extracts}

The plant sample in fine powder form $(3 \mathrm{~kg})$ of $\mathrm{H}$. strigosum was macerated in methanol solvent for 15 days. After the maceration, the soluble fractions in methanol were filtered and the filtrate was concentrated at $40^{\circ} \mathrm{C}$ by using rotary evaporator to give crude extract (Yield $=150 \mathrm{gm}$ ). The 50 gm crude extract was then dissolved in $150 \mathrm{~mL}$ of distilled water and sequentially portioned with $150 \mathrm{~mL}$ of $\mathrm{n}$-hexane, $150 \mathrm{~mL}$ of chloroform and $150 \mathrm{~mL}$ of ethyl acetate. The n-hexane, chloroform, ethyl acetate and aqueous solutions yielded 1.9, 1, 0.5 and $8 \mathrm{gm}$ of solvent free extracts, respectively. The concentrated extracts of methanol, n-hexane, ethyl acetate, chloroform and water were transferred to sample vials and stored at $-4^{\circ} \mathrm{C}$ for further analysis.

Total phenolic content

Total phenolic contents were determined using Folin-Ciocalteu method ${ }^{12,13}$. Briefly, $1 \mathrm{~mL}$ solution of each solvent extract (methanol, $\mathrm{n}$-hexane, ethyl acetate, chloroform and aqueous) was mixed with $7.5 \mathrm{~mL}$ of double deionized water, $500 \mu \mathrm{L}$ of Folin-ciocalteu reagent and one $\mathrm{mL}$ of $5 \% \mathrm{Na}_{2} \mathrm{CO}_{3}$. The reaction mixture was incubated at room temperature for 90 minutes. Absorbance of reaction mixture was measured at $760 \mathrm{~nm}$ by using UV-Vis spectrophotometer (Lambda EZ 201, Perkin Elmer, USA). The content of phenolics was expressed as $\mu \mathrm{g}$ gallic acid equivalents (GAEs) per mg of extract.

Analysis of phenolic compounds

The hydrolysis of $H$. strigosum extracts was performed as described previously ${ }^{14}$. Briefly, the test samples $(50 \mathrm{mg})$ of each extract was dissolved in $24 \mathrm{~mL}$ methanol and was homogenized. $16 \mathrm{~mL}$ distilled water was added followed by $10 \mathrm{~mL}$ of $6 \mathrm{M} \mathrm{HCl}$. The mixture was then thermostated for $2 \mathrm{hr}$ at $95^{\circ} \mathrm{C}$. The final solution was filtered using $0.45 \mu \mathrm{m}$ nylon membrane filter (Biotech, Germany) prior to high performance liquid chromatography (HPLC) analysis.

The separation of plant samples on gradient HPLC (LC-10A, SHIMADZU, JAPAN ) was performed using shim-pack CLC-ODS (C118), $25 \mathrm{~cm} \mathrm{X} 4.6 \mathrm{~mm}$, $5 \mu \mathrm{m}$ column. The chromatographic separation was carried out using as mobile phase gradient : $\mathrm{A}(\mathrm{H} 2 \mathrm{O}$ : Acetic acid-94:6, $\mathrm{pH}=2.27)$, $\mathrm{B}$ (acetonitrile $100 \%)$. The gradient used was $15 \%$ solvent $B(0-15 \mathrm{~min}), 45 \%$ solvent $\mathrm{B}(15-30 \mathrm{~min})$ and $100 \%$ solvent B $(35-45 \mathrm{~min})$ with $1 \mathrm{~mL} / \mathrm{min}$ flow rate. The UV- visible detector $(\lambda \max 280 \mathrm{~nm}$ ) was used for separation of phenolic compounds. The identification of phenolic compounds was established by comparing the retention time and UV-Visible spectra of the peaks with those previously obtained by injection of standards. The quantification was performed by external calibration.

Alpha amylase inhibition assay

Antidiabetic activity of each extract obtained from methanol and different solvent (n-Hexane, ethyl acetate, chloroform and aqueous) fractions of $H$. strigosum was determined by $\alpha$-amylase assay as described previously ${ }^{15}$. The $500 \mu \mathrm{L}$ of different concentrations $(10$ to $250 \mu \mathrm{g} / \mathrm{mL}$ ) of methanol extract and each solvent fraction was mixed in $500 \mu \mathrm{L}$ solution of alpha amylase enzymes and then incubated at $25^{\circ} \mathrm{C}$ for 10 minutes. $500 \mu \mathrm{L}$ of starch solution was added in above solution and incubated at room temperature for 10 minutes. Then 1 
$\mathrm{mL}$ of DNSA solution was added in the mixture and placed in boiling water bath for 5 minutes and cooled at room temperature. $10 \mathrm{~mL}$ water was added for dilution and measured the absorbance at $540 \mathrm{~nm}$ wavelength. The percentage inhibition was calculated by following formula

$$
\mathbf{I}(\% \text { age })=\left\{\left(\mathbf{A}_{\text {blank }}-\mathbf{A}_{\text {sample }}\right) / \mathbf{A}_{\text {blank }}\right\} \times 100
$$

Where $A_{\text {blank }}$ and $A_{\text {sample }}$ are the absorbance of the blank and test sample respectively.

DPPH (2,2-diphenyl-1-picrylhydrazyl) free radical scavenging assay

2,2-diphenyl-1-picrylhydrazyl (DPPH) free radical scavenging assay was used to estimate antioxidant potential of $H$. strigosum extract solutions ${ }^{16}$. Briefly, $4 \mathrm{~mL}$ of methanol solution of 2,2-diphenyl-1-picrylhydrazyl $(0.1 \mathrm{mM})$ was mixed with $1 \mathrm{~mL}$ of different dilutions (10 to $250 \mu \mathrm{g} / \mathrm{mL}$ ) of each extract. The reaction mixture was incubated in dark room for 30 minutes. Then the absorbance was measured at $515 \mathrm{~nm}$ with UV-Vis spectrophotometer (Lambda EZ 201, Perkin Elmer, USA). The inhibition percentage of 2,2-diphenyl-1picrylhydrazyl (DPPH) radicals was calculated as:

\section{Inhibition $(\%)$ of DPPH radicals $=\mathrm{Ac}-\mathrm{As} / \mathrm{Ac}$ X 100}

Where Ac is absorbance of control (reaction in which all reagents participated except plant extract) and As is absorbance of sample (plant extract).

\section{Statistical analysis}

All the assayed for methanolic crude extract and various fractions was performed in triplicate and represented in mean and standard error. One Way Analysis of variance (ANOVA) technique was used for the statistical analysis.

\section{RESULTS AND DISCUSSIONS}

\section{Total phenolic contents}

It is widely accepted that phenolic compounds are major contributors of antioxidant activity ${ }^{17}$. In current study total phenolic contents of methanol extract and different solvent (Hexane, chloroform, ethyl acetate and aqueous) fractions of $H$. strigosum were determined using Folin-Ciocalteu method, which is described in different pharmacopieias ${ }^{18}$. The reaction is based upon the fact that phosphomolybedate and phosphotungstate in the reaction mixture react with phenolic compounds in the plant sample and generate a blue chromophere that had maximum light absorption at $760 \mathrm{~nm}^{19}$. Higher the extent of phenolic compounds in the plant sample, greater will be the intensity of blue pigment and so on. It is evident from the results (Table.1) that total phenolic contents of methanol extract and different solvent fractions of $H$. strigosum ranged from $12.81 \pm 0.93$ to $84.50 \pm 0.06 \mu \mathrm{g} \mathrm{GAE} / \mathrm{mg}$ of plant extract. Methanol extract of $H$. strigosum exhibited significantly higher $(P<0.05)$ total phenolic contents $(84.50 \pm 0.06 \mu \mathrm{g} \mathrm{GAE} / \mathrm{mg}$ of plant extract). These results are in agreement with previous study, in which maximum amount of total phenolic contents was examined in methanol extract of medicinal plant ${ }^{20,21}$. Among the other solvent fractions, aqueous fraction ( $70.41 \pm 0.82 \mu \mathrm{g} \mathrm{GAE} / \mathrm{mg}$ of plant extract) had the highest total phenolic contents followed by ethyl acetate $(31.99 \pm 1.57 \mu \mathrm{g} \mathrm{GAE} /$ $\mathrm{mg}$ of plant extract), chloroform $(25.36 \pm 2.44 \mu \mathrm{g} \mathrm{GAE} / \mathrm{mg}$ of plant extract) and n-hexane $(12.81 \pm 0.93 \mu \mathrm{g} \mathrm{GAE} / \mathrm{mg}$ of plant extract) fractions. Difference in total phenolic contents among different solvent fractions might be linked to chemical nature of extracting solvent ${ }^{22}$. Significant difference $(P<0.05)$ was observed among total phenolic contents of different fractions of $H$. strigosum, with regard to variation in extracting solvent. These results are in accordance with previous study, which showed strong influence of extracting solvents on extraction of total phenolic compounds from Limnophila aromatica herb ${ }^{23}$. As the FC-method does not provide complete quantitative and qualitative profile of phenolic compounds, therefore, HPLC study for determination of individual of phenolic compounds was obligatory.
Table. 1. Total phenolic contents, antidiabetic activity and antioxidant activity of different solvent fractions of $\mathrm{H}$. strigosum

\begin{tabular}{|c|c|c|c|}
\hline $\begin{array}{c}\text { Heliotropium } \\
\text { strigosum } \\
\text { solvent } \\
\text { fractions } \\
\text { and positive } \\
\text { controls }\end{array}$ & $\begin{array}{c}\text { Total phenolic } \\
\text { contents } \\
*(\mu \mathrm{g} \text { QE/ } \\
\text { mg of plant } \\
\text { extract })\end{array}$ & $\begin{array}{c}\alpha \text {-amylase } \\
\text { inhibition } \\
\text { activity, } \\
\mathrm{IC}_{50}(\mu \mathrm{g} / \mathrm{mL})\end{array}$ & $\begin{array}{c}\text { DPPH } \\
\text { inhibition } \\
\text { activity, } \\
\mathrm{IC}_{50}(\mu \mathrm{g} / \mathrm{mL})\end{array}$ \\
\hline Methanol & $84.50 \pm 0.06^{\mathrm{a}}$ & $8.97 \pm 0.01^{\mathrm{b}}$ & $10.45 \pm 0.01^{\mathrm{d}}$ \\
\hline Aqueous & $70.41 \pm 0.82^{\mathrm{b}}$ & $20.04 \pm 2.65^{\mathrm{c}}$ & $28.41 \pm 0.36^{\mathrm{a}}$ \\
\hline Ethyl acetate & $31.99 \pm 1.57^{\mathrm{c}}$ & $27.79 \pm 1.74^{\mathrm{a}}$ & $32.16 \pm 1.74^{\mathrm{b}}$ \\
\hline Chloroform & $25.36 \pm 2.44^{\mathrm{d}}$ & $56.87 \pm 0.35^{\mathrm{e}}$ & $45.37 \pm 0.92^{\mathrm{c}}$ \\
\hline Hexane & $12.81 \pm 0.93^{\mathrm{e}}$ & $194.8 \pm 0.59^{\mathrm{d}}$ & $100 \pm 0.15^{\mathrm{e}}$ \\
\hline Acrobose & --- & $3.06 \pm 0.08^{\mathrm{ab}}$ & ---- \\
\hline Ascorbic acid & ---- & ---- & $4.15 \pm 0.05^{\mathrm{f}}$ \\
\hline
\end{tabular}

$(----)=$ Not tested. Values are Mean \pm SD (Standard deviation) of three samples of each extract, analyzed individually in triplicates. Mean with different superscript letters in the same column indicate significant difference $(P<0.05)$ among solvent extracts tested.

\section{Reverse phase high performance liquid chromatographic (RP-HPLC)} analysis

The most suitable tool for chemical characterization of phenolic compounds from natural products is the HPLC analysis ${ }^{24}$, therefore in present study crude methanol extract and different solvent fractions (Hexane, chloroform, ethyl acetate and aqueous) of $H$. strigosum were analyzed for presence of eleven different phenolic compounds including chromotropic acid, quercetin, Trans 4-hydroxy-3-methoxy cinamic acid, vanillic acid, gallic acid, caffeic acid, $\mathrm{m}$-coumaric acid, $\mathrm{p}$ - coumaric acid, syringic acid, sinapic acid, ferulic acid and chlorogenic acid using reverse phase high performance liquid chromatography (RP-HPLC). The results are shown in Table. 2. Chromotropic acid $(86.16 \mu \mathrm{g} / \mathrm{g}$ of dry plant material) was found to be major phenolic compound in methanol extract followed by gallic acid (55.98 $\mu \mathrm{g} / \mathrm{g}$ of dry plant material), vanillic acid $(38.58 \mu \mathrm{g} / \mathrm{g}$ of dry plant material), syringic acid $(19.46 \mu \mathrm{g} / \mathrm{g}$ of dry plant material), ferulic acid $(8.88 \mu \mathrm{g} / \mathrm{g}$ of dry plant material), p-coumaric acid $(8.45$ $\mu \mathrm{g} / \mathrm{g}$ of dry plant material), quercetin $(6.44 \mu \mathrm{g} / \mathrm{g}$ of dry plant material), caffeic acid $(6.26 \mu \mathrm{g} / \mathrm{g}$ of dry plant material) and sinapic acid $(2.48 \mu \mathrm{g} / \mathrm{g}$ of dry plant material), respectively. Chromotropic acid $(72.58 \mu \mathrm{g} / \mathrm{g}$ of dry plant material) was the major phenolic compound of aqueous fraction followed by vanillic acid $(35.24 \mu \mathrm{g} / \mathrm{g}$ of dry plant material), gallic acid $(32.83 \mu \mathrm{g} / \mathrm{g}$ of dry plant material), syringic acid ( $20.62 \mu \mathrm{g} / \mathrm{g}$ of dry plant material), trans-4-hydroxy-3methoxy cinamic acid $(10.14 \mu \mathrm{g} / \mathrm{g}$ of dry plant material), $m$-coumaric acid $(8.09 \mu \mathrm{g} / \mathrm{g}$ of dry plant material) and $p$-coumaric acid $(5.72 \mu \mathrm{g} / \mathrm{g}$ of dry plant material), ferulic acid $(4.97 \mu \mathrm{g} / \mathrm{g}$ of dry plant material) and quercetin $(4.47 \mu \mathrm{g} / \mathrm{g}$ of dry plant material). Ethyl acetate and chloroform fractions were found to be rich in trans-4-hydroxy-3-methoxy cinnamic acid $(40.23 \mu \mathrm{g} / \mathrm{g}$ of dry plant material) and syringic acid (18.16 $\mu \mathrm{g} / \mathrm{g}$ of dry plant material), respectively. Chlorogenic acid $(9.70 \mu \mathrm{g} / \mathrm{g}$ of dry plant material) and quercetin $(1.25 \mu \mathrm{g} / \mathrm{g}$ of dry plant material) were minor phenolic constituents of ethyl acetate and chloroform fractions. From the hexane fraction chromotropic acid $(10.20 \mu \mathrm{g} / \mathrm{g}$ of dry plant material) was found to be major phenolic acid followed by gallic acid $(4.45 \mu \mathrm{g} / \mathrm{g}$ of dry plant material) and ferulic acid $(9.70 \mu \mathrm{g} / \mathrm{g}$ of dry plant material). The extent of other phenolic compounds in n-hexane fraction was less than 1 ( $\mu \mathrm{g} / \mathrm{g}$ of dry plant material).

Many scientific studies had revealed that amount of phenolic components is diversified at sub cellular level in plants ${ }^{25}$. Phenolic compounds are potent marker of antioxidant activity and had beneficial effects on human health ${ }^{26}$. The presence of phenolic compounds in several plants was reported to possess anti-inflammatory, antidiabetic, antioxidant and several others therapeutic activities ${ }^{27,28}$. Therefore, in current study, the excellent antioxidant potential of methanol extract might be correlated with higher level of phenolic compounds in it. These results are similar to earlier study, who explored a strong correlation between antioxidant activity and phenolic compounds ${ }^{29}$. 
Table. 2. High performance liquid chromatography (HPLC) study of methanol, aqueous, ethyl acetate, chloroform and hexane fractions of $H$. strigosum for identification of polyphenolic compounds.

\begin{tabular}{|c|c|c|c|c|c|}
\hline \multirow{2}{*}{$\begin{array}{l}\text { Phenolic compounds } \\
\qquad(\mu \mathrm{g} / \mathrm{mg})\end{array}$} & \multicolumn{5}{|c|}{ Solvent extracts } \\
\hline & Methanol & Aqueous & Ethyl acetate & Chloroform & Hexane \\
\hline Chromatotropic acid & $86.16 \pm 0.04^{\mathrm{a}}$ & $72.58 \pm 0.13^{\mathrm{c}}$ & $32.5 \pm 0.08^{\mathrm{b}}$ & $18.16 \pm 0.21^{\mathrm{d}}$ & $10.20 \pm 0.04^{\mathrm{e}}$ \\
\hline Quercetin & $6.44 \pm 0.01^{b}$ & $4.47 \pm 0.05^{\mathrm{d}}$ & ---- & $1.25 \pm 0.02^{\mathrm{c}}$ & $0.25 \pm 0.01^{\mathrm{c}}$ \\
\hline $\begin{array}{c}\text { Trans 4-hydroxy-3-methoxy } \\
\text { cinamic acid }\end{array}$ & $16.38 \pm 0.13^{\mathrm{c}}$ & $10.14 \pm 0.06^{\mathrm{b}}$ & $40.23 \pm 0.04^{\mathrm{a}}$ & ---- & $0.73 \pm 0.02^{\mathrm{f}}$ \\
\hline Vanillic acid & $38.58 \pm 0.06^{\mathrm{a}}$ & $35.24 \pm 0.11^{\mathrm{c}}$ & ---- & ---- & --- \\
\hline Gallic acid & $55.98 \pm 0.21^{\mathrm{d}}$ & $32.83 \pm 0.07^{\mathrm{a}}$ & ---- & $4.59 \pm 0.06^{\mathrm{b}}$ & $4.45 \pm 0.13^{\mathrm{b}}$ \\
\hline Caffeic acid & $6.26 \pm 0.09^{c}$ & ---- & $23.42 \pm 0.26^{\mathrm{f}}$ & $2.19 \pm 0.01^{\mathrm{a}}$ & ---- \\
\hline m-coumeric acid & $10.23 \pm 0.05^{\mathrm{d}}$ & $8.09 \pm 0.31^{\mathrm{c}}$ & $21.74 \pm 0.43^{b}$ & --- & ---- \\
\hline p-coumeric acid & $8.45 \pm 0.49^{\mathrm{a}}$ & $5.72 \pm 0.01^{\mathrm{b}}$ & ---- & $1.67 \pm 0.08^{c}$ & ---- \\
\hline Syringic acid & $19.46 \pm 0.12^{\mathrm{a}}$ & $20.62 \pm 0.08^{\mathrm{a}}$ & ---- & $11.75 \pm 0.02^{\mathrm{c}}$ & $0.80 \pm 0.04^{\mathrm{d}}$ \\
\hline Sinapic acid & $2.48 \pm 0.01^{\mathrm{e}}$ & ---- & ---- & ---- & $0.25 \pm 0.01^{\mathrm{a}}$ \\
\hline Ferulic acid & $8.88 \pm 0.07^{\mathrm{a}}$ & $4.97 \pm 0.03^{b}$ & ---- & ---- & $3.38 \pm 0.09^{\mathrm{c}}$ \\
\hline Chlorogenic acid & ---- & ---- & $9.70 \pm 0.09$ & ---- & ---- \\
\hline
\end{tabular}

$(---)=$ Not detected. Data are shown as Mean \pm SD of triplicate determinations. Mean with different superscript letters in the same row indicate significant difference $(P<0.05)$ in amount $(\mu \mathrm{g} / \mathrm{mg})$ of same phenolic compound with regard to different solvent (methanol, aqueous, ethyl acetate, chloroform and $\mathrm{n}$-hexane) extract.

\section{Antidiabetic activity (alpha amylase inhibition assay)}

In present research work ,methanol extract and different solvent (n-hexane, chloroform, ethyl acetate and aqueous) fractions of H. strigosum were investigated for their potential against the inhibition of activity of $\alpha$-amylase enzyme. It is depicted from the results (Fig. 1) that methanol extract and four different solvent fractions of H. strigosum significantly inhibit the activity of $\alpha$-amylase enzyme in dose dependent manner ( 10 to $250 \mu \mathrm{g} / \mathrm{mL}$ ) and could be used for the treatment of postprandial hyperglycemia. We examined minimum inhibition of $\alpha$-amylase enzyme activity (\%) in methanol extract and different solvent fractions at $10 \mu \mathrm{g} / \mathrm{mL}$, while maximum inhibition (\%) of $\alpha$-amylase enzyme activity was examined at dose of $250 \mu \mathrm{g} / \mathrm{mL}$. Our findings are consistent with previous study, in which increase in $\alpha$-amylase enzyme inhibition (\%) was examined with increase in concentration of Urtica dioica and Juglans regiultsa extracts ${ }^{30}$. Overall, the order of antidiabetic activity of different solvent fractions was as: methanol $>$ aqueous $>$ ethyl acetate $>$ chloroform $>$ n-hexane. Maximum antidiabetic potential of methanol extract could be due to presence of higher extent of phenolic compounds which would likely to offer more potential for inhibition of porcine pancreatic $\alpha$ - amylase. Variation in antidiabetic activity of different solvent fractions of $H$. strigosum might be attributed to difference in chemical compounds extracted with different nature of solvents.

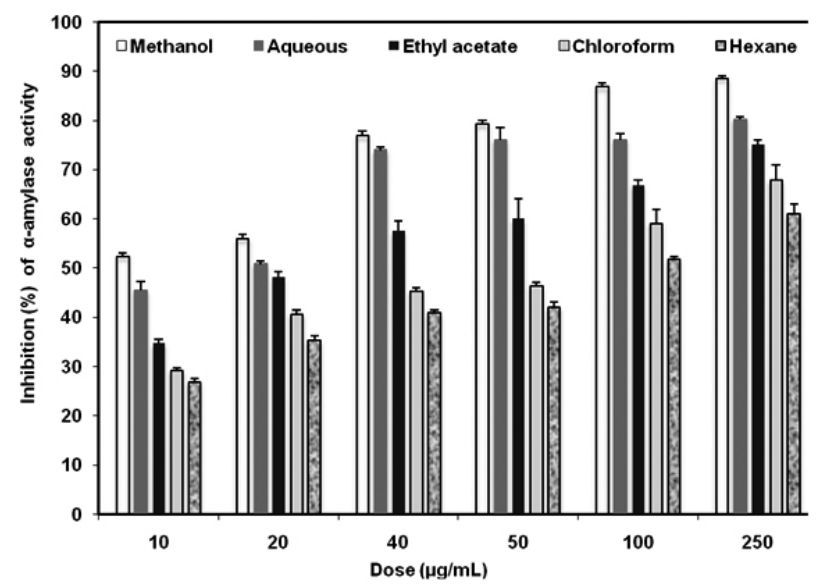

Fig. 1. Inhibition (\%) of $\alpha$-amylase by methanol, aqueous, ethyl acetate, chloroform and hexane extracts of $H$. strigosum

\section{Antioxidant activity (DPPH assay)}

2,2-diphenyl-1-picrylhydrazyl (DDPH) scavenging assay was used to characterize the antioxidant potential of crude extract (methanol) and different solvent fractions (n-hexane, ethyl acetate, chloroform and aqueous) of H. strigosum. DPPH is single electron transfer mechanism which had been used to assess antioxidant potential of wide variety of plant extracts ${ }^{31}$. This assay is based on transfer of electron from antioxidant compound to scavenge 2,2-diphenyl-1-picrylhydrazyl radicals in the reaction mixture ${ }^{32}$. As a result the color of 2,2-diphenyl-1-picrylhydrazyl (DPPH) solution changes from purple to yellow ${ }^{33}$. Stronger the intensity of yellow color higher will be the ability of plant extract to scavenge 2,2-diphenyl-1-picrylhydrazyl radicals and ultimately stronger will be the antioxidant activity. In current study antioxidant potency of crude extract (methanol) and different solvent fractions (n-Hexane, ethyl acetate, chloroform and aqueous) of H. strigosum was examined in dose dependant manner $(10$ to $250 \mu \mathrm{g} / \mathrm{mL}$ ). The results (Fig. 2) showed an increase in 2,2-diphenyl-1-picrylhydrazyl radicals scavenging ability with increase in dose of methanol extract and all solvent fractions of $H$. strigosum. This trend is in line previous finding, who demonstrated an increase in 2,2-diphenyl-1-picrylhydrazyl radical scavenging activity with increase in dose of plant extracts ${ }^{34}$. In our study methanol extract $\left(\mathrm{IC}_{50}=10.45 \mu \mathrm{g} /\right.$ $\mathrm{mL})$ exhibited significantly $(P<0.05)$ higher 2,2-diphenyl-1-picrylhydrazyl radical (DPPH) scavenging activity than aqueous ethyl acetate, chloroform and n-hexane fractions. Overall, the hierarchy of 2,2-diphenyl-1-picrylhydrazyl radical (DPPH) scavenging activity of methanol extract and four different solvent fractions was as: methanol extract $\left(\mathrm{IC}_{50}=10.45 \mu \mathrm{g} / \mathrm{mL}\right)>$ aqueous fraction $\left(\mathrm{IC}_{50}=28.41 \mu \mathrm{g} / \mathrm{mL}\right)>$ ethyl acetate fraction $\left(\mathrm{IC}_{50}=32.16 \mu \mathrm{g} / \mathrm{mL}\right)$ $>$ chloroform fraction $\left(\mathrm{IC}_{50}=45.37 \mu \mathrm{g} / \mathrm{mL}\right)>\mathrm{n}$-hexane fraction $\left(\mathrm{IC}_{50}=100\right.$ $\mu \mathrm{g} / \mathrm{mL}$ ). Our results are in line with previous findings, which revealed that antioxidant activity of plants dependent on extracting solvent ${ }^{35}$.

\section{CONCLUSION}

In conclusion, our study is first report on phenolic composition and antidiabetic activity of different solvent extracts of $H$. strigosum. The results of current study revealed that methanol extract had consistently high total phenolic contents, number of individual phenolic compounds, antioxidant as well as antidiabetic activities. The knowledge of phenolic composition in different solvent (methanol, aqueous, ethyl acetate, chloroform and aqueous) fractions will help to explore their potential as source of natural antioxidants. Moreover, the comparison of phenolic composition among solvents of variable polarity will help to optimize the solvent for extraction of phenolic compounds. The considerable antidiabetic and antioxidant activities of different extracts may assist in preparation of herbal drugs for treatment diabetes and oxidative stress based disorders. 


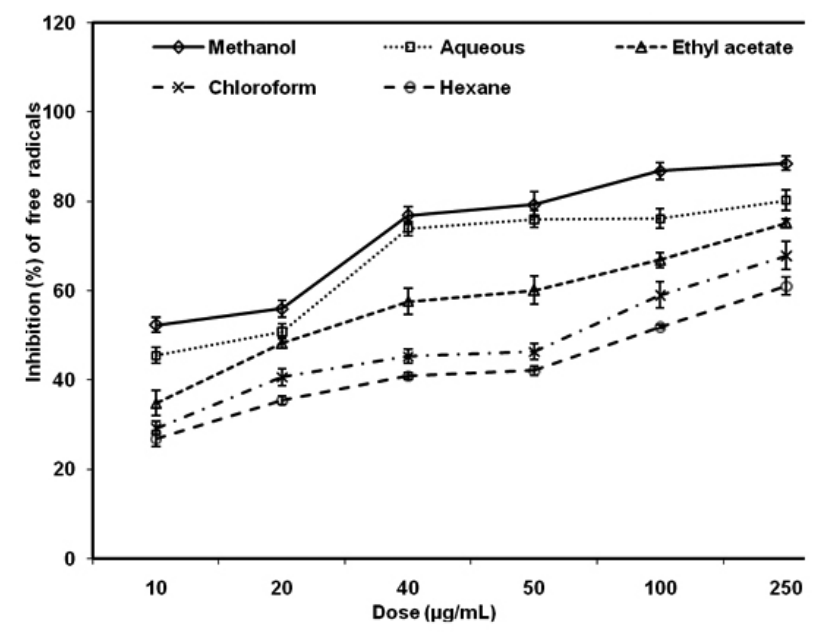

Fig. 2. Inhibition (\%) of free (2,2-diphenyl-1-picrylhydrazyl) radicals by methanol, aqueous, ethyl acetate, chloroform and hexane extracts of $H$. strigosum.

\section{ACKNOWLEDGEMENT}

The authors thankfully acknowledge the cooperation extended by staff of Central Hi-Tech Laboratory, University of Agriculture, Faisalabad, Pakistan.

\section{REFERENCES}

1. N. Goyal, S.K. Sharma. Intern. J. Green Pharm. 8217 (2014).

2. M. Hameed, M. Ashraf, F. Al-Quraiany, T. Nawaz, M.S.A. Ahmad, A. Younis, N. Naz. Pak. J. Bot. 4339 (2011)

3. S. Zakir, Z. Ullah, S.A. Khattak, Z. Iqbal. Peshawar Uni. Teach. Assoc J. 1273 (2005).

4. K. Srinivas, M.E. Rao, S.S. Rao. Indian J Pharmacol. 3237 (2003).

5. B. Singh, P.M. Sahu, C.C. Jain, S. Singh. Pharm Biol. 40581 (2002).

6. K.S. Betanabhatla, S.R. Jasmin, R. Karthik, J. Raamamurthy, A.J. Christina, S. Sasikumar. Pharmacologyon 3438 (2007).

7. H.T. Simonsen, J.B. Nordskjold, U.W. Smitt, P. Palpu, P. Joshi, G. Varughese. J. Ethnopharmacol. 74195 (2001).

8. S.K. Sharma, N. Goyal. Zhong Xi Yi Jie He Xue Bao 10555 (2012).

9. J.S. Reddy, P.R. Rao, M.S. Reddy. J. Ethnopharmacol. 79249 (2002).

10. S.M. Shah, S. Hussain, A.U. Khan, A.U. Shah, H. Khan, F. Ullah, Barkatullah. Toxicol. Ind. Health. 31429 (2015).

11. S. Hussain, M. Jamil, F. Ullah, A. Khan, F. Ullah, M. Arfan, S. Ahmad, L. Khatoon. 457738 (2010).

12. L.K. Jagadish, V.V. Krishnan, R. Shenbhagaraman, V. Kaviyarasan. Afri. J. Biotech. 8654 (2011).

13. K. Slinkard, V.L. Singleton. Amer. J. Enol. Viti. 2849 (1997).

14. M.S. Pak-Dek, A. Osman, N.G. Sahib, N. Saari, M. Markom, A.A. Hamid, F. Anwar. J. Med. Plant. Res. 205050 (2011.

15. H. Ali, P.J. Houghton, A. Soumyanath. J. Ethnopahrmacol 107449 (2006).

16. A. Ashraf, R.A, Sarfraz, A. Mahmood, M.U. Din. Indus. Crop. Prod. 74 $241(2015)$.

17. A. Sathya, P. Siddhuraju. Asian Pac. J. Trop Med. 5757 (2012).

18. S.G. Verza, C. Pavei, G.C. Ortega. J. Braz. Chem. Societ. 18 (2008).

19. P. Schofield, D.M. Mbugua, A.N. Pell AN. Ani. Feed Sci. Tech. 9121 (2001).

20. O. Yumrutas, D. Saadet, D. Saygideger. J. Appl. Pharm. Sci. 236 (2012).

21. S. Sahin, E. Isik, C. Demir. Intern. Schol. Res. Net. 20127 (2012).

22. A. Ashraf, R.A. sarfraz, F. Anwar, S.A. Shahid, K.M. Alkharfy. Pak. J. Bot. 47367 (2015).

23. Q.D. Do, A.E. Angkawijaya, P.L. Tran-nguyen, I.H. Hunh, F.E. Soetaredio, S. Ismadjj, H.S. Ju. Arab. J. Chem. 22296 (2014).

24. G. Cimpan, S. Gocan. J. Liq. Chromat. Related Tecnol. 252225 (2002).

25. Y. Randhir, T. Lin, K. Shetty. Asia. Pac. J. Clin. Nut. 13295 (2000).

26. K.B. Pandey, S.I. Rizvi. Oxid. Med. Cell. Longev. 2270 (2009)

27. S. Saravanan, T. Parimelazhagan. Food Sci. Human Well. 256 (2014).

28. G. Zhang, M. Baba, Y. Okada, T. Okuyama, L.J. Wu, L.B. Zhan. BMC Complement. Altern. Med. 14422 (2014).
29. X. Li, X. Wu, L. Huang. Molecules 145349 (2009).

30. M. Rahimzadeh, S. Jahanshahi, S. Moein, M.R. Moein. Iran. J. Basic. Med. Sci. 17465 (2014).

31. C. Proestos, K. Lytoudi, O.K. Mavromelanidou, P. Zoumpoulakis, V.J. Sinanoglou . Antioxid. 211 (2013).

32. S.S. Kumar, K.I. Priyadarsini, K.B. Sainis KB. Redox. Rep. 735 (2002).

33. H. Amiri. Evidence-Based Compl. Altern. Med. 20128 (2012).

34. A. Ashraf, R.A. Sarfraz, M.A. Rashid, M. Shahid. J. Food Drug Ana. 23 109 (2015).

35. M.A. Hossain, M.D. Shah. Arab. J. Chem. 866 (2015). 